\title{
Provenancing archaeological ceramics in the southern Andes: evaluating a combined $\mathrm{Sr}-\mathrm{Nd}$-Pb isotope approach
}

\author{
Petrus le RouX ${ }^{1}$, Cecilia Frigolé ${ }^{2}$, Lorena \\ SANHUEZA $^{3}$, FERNANDA FALABELLA ${ }^{3}$, ANDRES \\ TRONCOSO $^{3}$, LuIS CORNEJO ${ }^{4}$ AND RAMIRO BARBERENA ${ }^{2}$ \\ ${ }^{1}$ Dept of Geological Sciences, University of Cape Town, \\ South Africa petrus.leroux@uct.ac.za \\ ${ }^{2}$ CONICET. Laboratory of Human Paleoecology, National \\ University of Cuyo, Argentina \\ ${ }^{3}$ Dept of Anthropology, University of Chile, Chile \\ ${ }^{4}$ Dept of Anthropology, Alberto Hurtado University, Chile
}

Interactions between past human societies can be deciphered through the characteristics of their recovered artefacts, if it is possible to "read" these in enough detail. Ceramics, whether intact or shards, are often the most abundant surviving material obtained from archaeological sites. Being able to determine where such ceramics were manufactured, local versus non-local, is therefore a powerful first-order insight. Tracing ceramic provenance to a specific site of production is the ultimate goal.

In addition to established qualitative methods, e.g. visual description of patterns, quantitative analytical methods are increasingly employed to characterize ceramics and define distinct groupings based on fundamental chemical compositions. Key in this approach is the use of traditional geochemical analytical methods to determine radiogenic isotope compositions of ceramics. Ceramic manufacturing processes such as firing and wet grinding induce no significant variations in isotope systems like strontium, neodymium, and probably lead. Such isotope characterization therefore represents an effective fingerprint of ceramics, strictly depending on the geochemical composition of the raw materials used by different ceramic production sites.

Here we present preliminary results of an investigation of ceramics from the southern Andes (Argentina and Chile), were the analysis of $\mathrm{Sr}$ isotope compositions were complemented by $\mathrm{Nd}$ and $\mathrm{Pb}$ isotope ratio analyses. Combined $\mathrm{Sr}-\mathrm{Nd}-\mathrm{Pb}$ analysis on a single sample dissolution, significantly lowers the physical impact on artifact material. Thus expanding the geochemical tools available to provenance ceramic artifacts, and possibly locate sites of manufacture.

We critically assess whether it is worthwhile for studies of ceramic provenance in the southern Andes specifically to employ $\mathrm{Nd}$ and/or $\mathrm{Pb}$ isotope data in addition to $\mathrm{Sr}$ isotope data. 